\title{
PRÁTICA DE CARTEL NO BRASIL: UM ESTUDO SOBRE AS DECISÕES DO CADE E 0 PERFIL DAS CONDENAÇÕES POR CARTEL
}

Felipe Braga Albuquerque

Professor Dr. do Programa de Pós-Graduação em Direito (PGDIR) da Faculdade de Direito da Universidade Federal do Ceará (UFC).

Leonardo José Peixoto Leal

Professor dos cursos de Graduação em Direito da Universidade de Fortaleza e do Centro Universitário Estácio do Ceará. Doutorando em Direito pela Universidade Federal do Ceará. Advogado. Secretário-Geral da Comissão de Estudo e Defesa da Concorrência da OAB/CE. Vice-Presidente Nordeste da Federação dos PósGraduandos em Direito do Brasil - FEPODI.

\section{Resumo}

O objetivo deste trabalho é analisar a prática de cartéis no Brasil a partir da atuação do Conselho Administrativo de Defesa Econômica - CADE. O estudo conclui, com base em uma metodologia de pesquisa teórica e documental, que embora exista no Brasil uma boa estrutura administrativa de proteção ao ambiente concorrencial, fortalecida a partir da Lei 12.529/2011, é evidente a baixa consistência com a qual uma conduta de aporte tão grave vem sendo tratada ao longo dos anos. É certo que muitas são as dificuldades envolvidas na constatação dessa infração todavia não parece haver um trabalho consistente no âmbito nacional a esse respeito, restringindo-se as análise a situaçóes isoladas sugerindo a ocorrência de um trabalho feito por amostragem. Inicialmente, o trabalho aborda a defesa da concorrência no Brasil; em seguida é analisada a estrutura administrativa e o Sistema Brasileiro de Defesa da Concorrência (SBDC); após, estabelece-se um estudo sobre a prática de cartel, espécie de infração à ordem econômica, promovendo o levantamento dos casos julgados pelo Conselho Administrativo de Defesa Econômica (CADE) no período compreendido entre os anos de 2000 e 2013; por fim, faz-se uma análise crítica dos dados coletados.

\section{Palavras-chave}

Concorrência; Cartel; CADE. 


\section{Abstract}

The objective of this work is to analyze the cartel practice in Brazil, aiming to identify the effective use of the judiciary in control practices violations of the economic order. The study concludes, based on a methodology of theoretical and documentary research, that although there is in Brazil a good administrative structure to protect the competitive environment, this structure strengthened from the Law 12.529/2011, there remains a deficiency of knowledge of antitrust policy by the population, resulting in a small number of processes aimed at compelling infringing practices or work for the restoration of damage. Initially, the paper addresses the protection of competition in Brazil, and then analyzes the administrative structure and the Brazilian System of Competition Defense, after sets the focus on the analysis of cartel cases, sort of violation of the economic order, promoting the survey cases sentenced by the Administrative Council for Economic Defense - CADE between the years 2000 to 2013, and finally It is made a review analysis.

\section{Key words}

Defense; Competition; Cartel; CADE.

\section{Introdução}

A defesa da concorrência objetiva, na sua origem, favorecer um ambiente de mercado de "concorrência perfeita", ou seja, que nenhum dos agentes que se relacionam detenha poder suficiente, poder de mercado, para, sozinho, determinar aspectos como preço, produção, qualidade, investimento em inovação, dentre outros elementos relevantes.

Mas na realidade, o ambiente descrito acima é de difícil configuração devido ao fato de que há uma tendência de concentração no sistema capitalista ${ }^{1}$ de produção, uma vez que quanto maior for a empresa ou agente econômico, maiores seráo suas possibilidades de lucro com ampla perspectiva de reduçáo de custos. Dessa forma, a maior parte dos mercados estrutura-se em ambientes de "concorrência imperfeita" ou de estrutura "oligopolista" ou "monopolista". Além do fato da possibilidade de ocorrências de externalidades como a formação de conluio entre competidores, fato que elimina os benefícios de uma estrutura concorrencial.

Dentro desse contexto, uma política estatal de controle e defesa do ambiente concorrencial assume especial relevância uma vez que essa estrutura poderá propiciar a existência de um ambiente, o mais próximo possível, da estrutura de "concorrência perfeita" por meio de controle e fiscalização eficientes dos atos praticados no mercado, o que resulta,

1 No sentido do lucro ser determinante na concentraçấo de poder econômico (MOTA, 2007, p.70-71) 
em regra, ganhos positivos para a economia e para a sociedade, como redução de preços, melhoria de qualidade de produtos e serviços, aumento dos investimentos em inovação e tecnologia, entre outras possibilidades.

Recentemente, o SBDC foi reestruturado a partir da Lei 12.529 de 30 de novembro de 2011 que revogou a Lei 8.884 de 11 de junho de 1994 sendo constatável que, nos últimos anos, o sistema evoluiu, desenvolvendo um trabalho de excelência que se percebe tanto pelo aumento no número de processos, cujo objeto abrange atos de concentração, como de processos que tenham por objeto infraçóes à ordem econômica apreciados pelo Conselho Administrativo de Defesa Econômica (CADE).

As práticas lesivas à concorrência, além de causarem impactos negativos ao mercado, podem provocar danos concretos às pessoas nele presentes. Imagine-se, por exemplo, um cartel dos postos de combustíveis em um determinado município. Estima-se que, em média, um cartel acarrete um aumento de preço entre $10 \%$ e $20 \%$ do que seria praticado em um ambiente efetivamente competitivo. Dessa forma, todos os indivíduos que adquirirem combustível nesse município estarão sendo lesados ao comprarem combustível mais caro, significando um dano concreto experimentado pelos compradores.

Por conta de situações como essas é que a Lei 12.529/2011 estabelece que qualquer prejudicado poderá pleitear judicialmente a cessação de práticas de infração, bem como a reparação dos danos experimentados em razáo de qualquer conduta anticoncorrencial. Tão importante é a responsabilidade civil que a legislação estabeleceu a total independência entre as esferas civil e administrativa, não havendo qualquer vinculação direta entre a possível busca por reparação da tutela jurisdicional e a instauração ou não de processos administrativos junto ao SBDC.

Nesta direção, o presente trabalho objetiva analisar os casos julgados pelo CADE no período compreendido entre 2000 e 2013 envolvendo a prática de Cartel. A delimitaçáo temporal foi estabelecida a partir da facilidade de acesso a informaçáo junto ao portal eletrônico do CADE acerca dos julgados realizados, não estando disponíveis as informaçóes concretas de julgados anteriores a 2000.

Ressalte-se que a atuação do CADE próxima aos moldes atuais iniciou-se em 1995 a partir da vigência da Lei 8.884 de 11 de junho de 1994, que fortaleceu a defesa da concorrência no Brasil atribuindo maiores poderes e competências aos órgáos. Percebe-se, dessa forma, que a amostragem selecionada é bastante consistente, capaz de espelhar com segurança o perfil de atuação da autoridade antitruste brasileira acerca dessa matéria. Não foram incluídos dados de 2014 por ainda não estarem disponíveis, à época da coleta dos dados para pesquisa, as informaçôes consolidadas acerca de todos os julgados de 2014 .

Inicialmente, apresenta-se a estrutura do SBDC e suas principais formas de atuação; em seguida é feita uma análise da possibilidade de busca de reparação de danos sofridos 
em razão da prática de cartel. Em outro momento, abordam-se as condenaçôes do CADE realizadas ao longo do período 2000-2013.

Por fim, analisar com maior profundidade os resultados estabelecendo comparaçóes entre o número de processo julgados, a quantidade de processos de cartel, a quantidade efetiva de condenaçóes e a delimitação geográfica onda a prática infrativa era realmente realizada.

\section{Defesa da Concorrência no Brasil}

A defesa da concorrência, seus institutos e a tutela legal existentes, surgem como resposta do estado às falhas de mercado, ou seja, a dominaçáo de mercados por certo agente ou condutas gravosas, ou tendentes a causar gravames à economia. Nesse diapasão, assume o princípio constitucional da livre concorrência uma característica de política pública estatal, no sentido de ser instrumento capaz de promover o bem estar social e o desenvolvimento da economia com os seus benefícios, tais como: geração de emprego, aumento de arrecadação estatal, ganho de bem estar social, respeito à dignidade do consumidor, dentre vários outros. (GOLDBERG, 2006, p. 24; FORGIONI, 2012, p.188-192).

Atualmente $^{2}$, o Sistema Brasileiro de Defesa da Concorrência (SBDC) tem a atribuição de zelar pela defesa da concorrência e pelo respeito à Lei 12.529/2011. Referido diploma legal regulamenta a concorrência no mercado brasileiro, estruturando o SBDC, reformulado após a edição da Lei. De acordo com a Lei 12.529/2011, o CADE passou a contar com um Tribunal Administrativo, uma Superintendência Geral que assumiu as funçóes desempenhadas pela extinta Secretaria de Direito Econômico e um Departamento de Estudos Econômicos. O Tribunal Administrativo tem sua estrutura definida no art. $6^{\circ}$ da Lei consistindo em órgão decisório ${ }^{3}$.

A Superintendência Geral detém função investigatória de atuação prévia às instauraçóes de Processo Administrativo, enquanto que o Departamento de Estudos Econômicos exerce a atuação voltada para pesquisas e análises consultivas do mercado e do ambiente concorrencial. A Lei Antitruste, além de definir a atuação do SBDC, como exposto acima, prevê práticas abusivas à ordem econômica, bem como sançóes aplicáveis.

2 Anteriormente, o sistema era composto de estrutura tripartite, na égide da Lei 8.884 de 11 de junho de 1994, contando com o Conselho Administrativo de Defesa Econômica (CADE), como instância julgadora e decisória e as Secretarias de Direito Econômico do Ministério da Justiça e Secretaria de Acompanhamento Econômico do Ministério da Fazenda, como órgãos investigativos e consultivos.

3 Art. 6o O Tribunal Administrativo, órgão judicante, tem como membros um Presidente e seis Conselheiros escolhidos dentre cidadãos com mais de 30 (trinta) anos de idade, de notório saber jurídico ou econômico e reputação ilibada, nomeados pelo Presidente da República, depois de aprovados pelo Senado Federal. 
Importa destacar, entretanto, que diversamente do que ocorre com o Código Penal Brasileiro, por exemplo, a Lei antitruste não pode adotar um conceito de tipificaçáo da conduta, não havendo, portanto, nenhuma conduta de ilegalidade per si; o legislador dotou a chamada "regra de razão". Ou seja, é necessário que, no caso concreto, avalie-se e identifique-se o dano gerado ao mercado, não se tratando de simples verificação de nexo causal ou de culpabilidade, mas sim, do caso em si. Pode, inclusive, haver condutas não previstas na lei, mas que sejam gravosas ao mercado. Tal logística é tradicionalmente utilizada nas legislaçóes antitruste (HOVEMKAMP, 2005, p. 117).

Como exemplo da regra de razão, tem-se, dentre as práticas vedadas, o monopólio ou oligopólio, que consiste no domínio do mercado por uma só empresa ou por um grupo de empresas, sendo evidente que tal situação é prejudicial aos consumidores e ao funcionamento mercado. Entretanto, podem ocorrer situaçóes que justifiquem tal prática, como a necessidade do monopólio natural, a exemplo do que ocorre com o de petróleo ou energia elétrica, bem como por conta de exceçóes legais, como na exploração, em caráter exclusivo, concedida em caráter temporário pela concessão de patente (FORGIONI, 2012, p.194-195).

Na lógica da Lei 12.529/2011 pode-se dividir a atuação do SBDC em três vertentes principais: A primeira, o "controle de estruturas" ou a análise prévia de atos de concentração (fusóes, aquisiçóes, incorporaçóes de empresas), tendentes a gerar um excessivo poder de mercado ou uma estrutura monopolista. Segundo os critérios elencados no art. 88 da referida legislação, basicamente que pelo menos uma das empresas envolvidas na operação tenha faturamento bruto anual ou volume de negócios total superior a $\mathrm{R} \$$ $700.000,00$ (setecentos milhóes), e que pelo menos outra tenha faturamento ou volume de negócios superior a $\mathrm{R} \$ 90.000,00$ (noventa milhóes) as empresas que objetivarem empreender um ato desse tipo necessitam comunicar ao SBDC solicitando, assim, aprovação do ato.

A segunda, o "controle de condutas", que se relaciona mais diretamente com o objetivo desse trabalho, consistindo, assim, no acompanhamento e fiscalização do mercado para reprimir práticas tidas como ilícitos anticoncorrenciais na forma do art. 36 de Lei de defesa da concorrência. A terceira vertente, a "busca pela divulgação e conscientização de pessoas e empresas a respeito da existência da política de defesa da concorrência”.

\section{Cartel como Infração da Ordem Econômica}

A Lei $12.529 / 2011$ estabelece em seu art. $1^{\circ}$, parágrafo único que a coletividade é titular dos direitos tutelados pela respectiva legislação. De fato, não poderia ser diferente na medida em que, ainda que indiretamente, a todos interessa a existência de um ambiente concorrencial, em uma estrutura de mercado organizada que permita a efetividade de 
competição entre os agentes econômicos e os melhores resultados possíveis, sobretudo, em relação à qualidade dos produtos, serviços e preços competitivos.

Outro aspecto importante de referido dispositivo legal é a expressa remissão ao art. 170 da Constituição da República Federativa do Brasil de 05 de outubro de 1988 - CRFB/88. Não se pode olvidar que a defesa da concorrência faça parte de um contexto de intervenção do estado na economia, cenário esse que, por vezes, se complementa como também serve de limites aos extremos de cada âmbito contemplado, buscando promover um equilíbrio nos diversos interesses existentes nas relaçōes de mercado (GRAU, 2004, P. 311)

É evidente a posição adotada pelo legislador constituinte foi de defesa e incentivo à livre iniciativa, erigido esse princípio a primado da intervenção do estado na economia, estando a livre concorrência, nesse contexto, como instrumento de proteção do referido instituto. O legislador constituinte ainda reitera sua opção pela posição do estado como regulador ${ }^{4} \mathrm{da}$ economia e não como explorador direto da atividade econômica, colocando no art. $173 \mathrm{da} C R F B / 88^{5}$ tal possibilidade como verdadeira figura excepcional.

Em verdade, observa-se que a CRFB/88 é típico fruto do paradigma do Estado Democrático de Direito que busca mesclar e avançar perspectivas dos paradigmas de Estado Liberal e do Estado Social. Daí a recorrente crítica, talvez, de contrariedade aos preceitos estabelecidos no capítulo da ordem econômica da CRFB/88 como um todo, na medida em que a prevê, ao mesmo tempo, o direito à propriedade privada e a observância do princípio da função social da mesma, o direito à livre iniciativa conjugado com o respeito ao meio ambiente, a proteção do consumidor e a proteção da livre concorrência, dentre vários outros elementos limitadores. Em verdade, as políticas estatais de intervenção no âmbito das relaçóes privadas surgem da necessidade de efetivação do princípio da boafé que estabelece a prática desse elemento como pressuposto das relaçóes contratuais. (EHRHARDT JUNIOR, 2013, p.557)

Compreendido este contexto em que se insere a defesa da concorrência destaca-se, por oportuno, que sua natureza transindividual possibilita que, a partir dos elementos da Lei 12.529/2011, sejam tutelados direitos difusos, coletivos e individuais homogêneos, ou seja, direitos que transcendem ao individuo nos termos do conceito estabelecido pelo art. 81 da Lei 8.078 de 11 de setembro de 1990 - Código de Proteção e Defesa do Consumidor.

Há, assim, na defesa da concorrência, a possibilidade de que determinada conduta seja prejudicial a todos, numa perspectiva de direito difuso; ou apenas a um mercado

4 Art. 174. Como agente normativo e regulador da atividade econômica, o Estado exercerá, na forma da lei, as funçóes de fiscalização, incentivo e planejamento, sendo este determinante para o setor público e indicativo para o setor privado.

5 Art. 173. Ressalvados os casos previstos nesta Constituição, a exploração direta de atividade econômica pelo Estado só será permitida quando necessária aos imperativos da segurança nacional ou a relevante interesse coletivo, conforme definidos em lei. 
especifico, a partir de um grupo, categoria ou classe determinada, o quê caracterizaria um direito coletivo. Em todos os casos, é possível que as práticas lesivas à concorrência acarretem em dados e prejuízos, direitos a indivíduos envolvidos ou atingidos por certo setor da economia.

Nesta pesquisa, traz-se a discussão específica a respeito dos possíveis danos decorrentes de um cartel. A Lei 12.529/2011 traz a previsão de infraçôes à ordem econômica em seu art. $36^{6}$, por meio do qual estabelece como conduta passível de punição a prática de cartel assim entendida em seu $\$ 3^{\circ}$, I:

$\$ 3^{\text {o }}$ As seguintes condutas, além de outras, na medida em que configurem hipótese prevista no caput deste artigo e seus incisos, caracterizam infração da ordem econômica: I - acordar, combinar, manipular ou ajustar com concorrente, sob qualquer forma: a) os preços de bens ou serviços ofertados individualmente; b) a produção ou a comercialização de uma quantidade restrita ou limitada de bens ou a prestação de um número, volume ou frequência restrita ou limitada de serviços; c) a divisão de partes ou segmentos de um mercado atual ou potencial de bens ou serviços, mediante, dentre outros, a distribuição de clientes, fornecedores, regióes ou períodos;

d) preços, condiçóes, vantagens ou abstenção em licitação pública;

Tal disposição legal tem fundamento no próprio texto constitucional, que estabelece, claramente, a vedação a qualquer tipo de abuso do poder econômico, no art. $173 \$$ 4o: "A lei reprimirá o abuso do poder econômico que vise à dominação dos mercados, à eliminação da concorrência e ao aumento arbitrário dos lucros".

Nesse sentido, cartel pode ser definido como um acordo entre concorrentes com o intuito de eliminar a concorrência ou de garantir o maior lucro para os participantes em detrimento dos concorrentes, dos consumidores e da ordem econômica. Para Ivo Teixeira Gico Júnior (2007, p. 169), o significado de cartel está associado a "um acordo (...) entre 'produtores da mesma categoria' para suprimir a 'livre concorrência'”. No Brasil, a busca pela prova da ocorrência do cartel dominou por muitos anos a discussão sobre o tema. Havendo, conforme destaca Calixto Salomáo Filho (2002, p. 190), uma ausência de formulação de uma teoria jurídica dos cartéis, de proposição de elementos corretos, para se chegar a uma definição, e um conceito de cartel.

A lei antitruste, como já citada, segue a ótica da chamada regra de razão. Verifica-se isso também em elação às infrações à ordem econômica pela simples redação do art. 36, da

6 Art. 36. Constituem infração da ordem econômica, independentemente de culpa, os atos sob qualquer forma manifestados, que tenham por objeto ou possam produzir os seguintes efeitos, ainda que não sejam alcançados: I - limitar, falsear ou de qualquer forma prejudicar a livre concorrência ou a livre iniciativa; II - dominar mercado relevante de bens ou serviços; III - aumentar arbitrariamente os lucros; e IV - exercer de forma abusiva posiçáo dominante. 
Lei $12.529 / 2011$. Entretanto, os cartéis são usualmente classificados pela doutrina como a mais gravosa infração a ordem econômica, dada a quantidade de efeitos negativos decorrentes de sua prática, a dificuldade de comprovação e punição e, ainda, a inexistência, em regra, de eficiências econômicas existentes a partir de referida conduta. (GICO Jr., 2007)

Jairo Saddi e Armando Castelar Pinheiro (2005, p.358) defendem que, em relação aos cartéis, pode ser adotada a regra de ilegalidade per se pois a simples constatação de sua prática lesiva já é suficiente para que as autoridades adotem medidas de sanção às partes envolvidas, sem necessidade de se averiguar a regra de razão. Os danos decorrentes de um Cartel, em regra, são severos. Segundo estimativas do próprio Sistema Brasileiro de Defesa da Concorrência ${ }^{7}$, apenas no que diz respeito ao aspecto de preço, em média, um mercado cartelizado ostentará preços de $10 \%$ a $20 \%$ mais caros do que se houvesse uma estrutura de efetiva competição entre os agentes envolvidos no conluio.

Tal condição é evidência suficiente para dimensionar quantas pessoas podem ser atingidas por um Cartel. Como exemplo, imagine-se a situação de um cartel de combustíveis em uma determinada cidade. Todos os habitantes daquela localidade, bem como as pessoas que eventualmente lá estejam em deslocamento, pagarão um valor mais elevado por combustível. Além disso, poderá influir em outros aspectos com reflexo no preço de transporte público, táxis, fretes, serviços de entrega, dentre outras possibilidades.

No que diz respeito aos indivíduos que se sujeitam à aplicação da Lei 12.529/2011, mais uma vez o legislador optou por uma conceituação ampla, englobando a quase totalidade dos agentes econômicos a partir do art. 31 de referida Lei (FORGIONI, 2012, p. 144). A responsabilidade pelos atos praticados, conforme o art. 33 da Lei 12.529/2011 será das empresas envolvidas e, solidariamente, empresas eventualmente integrantes de grupos econômicos e dos sócios e administradores que poderão, em alguns casos, responder, inclusive, com seu patrimônio pessoal por intermédio do instituto da desconsideração da personalidade jurídica.

\section{Casos de Cartel Condenados pelo CADE entre 2000-2013}

Adiante, serão analisados os casos de cartel condenados pelo Tribunal Administrativo do Conselho Administrativo de Defesa Econômica (CADE) no período correspondente a (2000-2013). A partir dessa amostra constam em maioria casos julgados pelo sistema ainda sob a égide da legislação anteriormente aplicável, tendo a aplicação da lei mais recente sido iniciada apenas a partir de 2011. Como os fatos investigados eram pretéritos todos os atos objetos de análise dos processos trazidos para este artigo foram praticados na vigência da Lei $8.884 / 94$, sendo aplicada a lei nova apenas no que diz respeito aos aspectos processuais.

7 www.mj.gov.br 
Optou-se pela adoção dessa amostragem para possibilitar uma maior diversidade de casos e identificar entendimentos decorrentes de composiçóes variadas do Conselho ao longo dos anos. Aspecto interessante é verificar a sazonalidade da quantidade de casos de cartel a cada ano. A seguir, com o fim de facilitar a compreensão dos casos, a análise será dividida ano a ano a partir de 2000.

\subsection{Casos de Cartel Condenados em 2000}

No ano de 2000 foram identificados os seguintes casos:

\begin{tabular}{|l|l|l|}
\hline \multicolumn{1}{|c|}{$\mathbf{n}^{\mathbf{0}}$ do Processo } & \multicolumn{1}{c|}{ Julgamento } & Mercado Relevante afetado \\
\hline $08012.000792 / 99-16$ & PROCEDENTE & SÃO PAULO \\
\hline $08012.006030 / 99-51$ & PROCEDENTE & CAMPINAS - SP \\
\hline $008012.000952 / 99-82$ & PROCEDENTE & NÃO ENCONTRADO \\
\hline $08012.003128 / 98-67$ & PROCEDENTE & FLORIANOPOLIS \\
\hline
\end{tabular}

Tabela 1: Processos de Cartel Julgados pelo CADE em 2000. Fonte: www.cade.gov.br ${ }^{8}$

Identifica-se acima 4 (quatro) casos julgados procedentes pela condenação em cartel.

\subsection{Casos de Cartel Condenados em 2001}

A tabela a seguir indica os casos condenados pelo CADE em 2001 sobre a prática de cartel:

\begin{tabular}{|l|l|l|}
\hline \multicolumn{1}{|c|}{$\mathbf{n}^{\mathbf{0}}$ do Processo } & \multicolumn{1}{c|}{ Julgamento } & Mercado Relevante afetado \\
\hline $08000.026056 / 96-30$ & PROCEDENTE & RIO DE JANEIRO \\
\hline $08000.022994 / 97-79$ & PROCEDENTE & ESTADO DE SÃO PAULO \\
\hline $08012.007044 / 99-00$ & PROCEDENTE & PARANÁ \\
\hline $08012.000487 / 2000-40$ & PROCEDENTE & NACIONAL \\
\hline $08012.006504 / 97-11$ & PROCEDENTE & NACIONAL \\
\hline 200090009699 & PROCEDENTE & NÃO ENCONTRADO \\
\hline
\end{tabular}

Tabela 2: Processos de Cartel Julgados pelo CADE em 2001. Fonte: www.cade.gov.br

$\mathrm{Na}$ tabela acima identifica-se um aumento no número de casos condenados comparativamente ao ano 2000, havendo 6 (seis) condenaçóes por cartel.

8 Todas as tabelas foram criadas pelos autores do trabalho. 


\subsection{Casos de Cartel Julgados em 2002}

No ano de 2002 foram encontrados os seguintes condenados pelo CADE em matéria de Cartel:

\begin{tabular}{|l|l|l|}
\hline \multicolumn{1}{|c|}{ no do Processo } & \multicolumn{1}{c|}{ Julgamento } & \multicolumn{1}{c|}{ Mercado Relevante afetado } \\
\hline $08012.002299 / 2000-18$ & PROCEDENTE & SANTA CATARINA \\
\hline $08012.006492 / 97-25$ & PROCEDENTE & RIO GRANDE DO NORTE \\
\hline $08012.004372 / 2000-70$ & PROCEDENTE & CEARA \\
\hline $08012.004712 / 2000-89$ & PROCEDENTE & GOIAS \\
\hline $\begin{array}{l}\text { No } 08000.015515 / 97- \\
02\end{array}$ & PROCEDENTE & MATO GROSSO DO SUL \\
\hline $08012.004373 / 2000-32$ & PROCEDENTE & CEARA \\
\hline
\end{tabular}

Tabela 3: Processos de Cartel Julgados pelo CADE em 2002. Fonte: www.cade.gov.br

Com base na tabela acima é possível identificar que, embora haja tido uma redução significativa no número de julgados sobre a matéria comparativamente ao ano de 2001, visto que apenas 13 (treze) casos sobre cartel foram julgados ${ }^{9}$, a quantidade de condenaçóes se manteve igual - 6 (seis) condenaçóes. Tais evidências podem apontar tanto para um maior rigor da autoridade antitruste nos julgamentos da matéria como também um aprimoramento nas investigaçóes e obtenção de provas que possibilitem a efetiva condenação.

\subsection{Casos de Cartel Julgados em 2003}

No ano de 2003 foram identificados os seguintes casos condenados pelo CADE relativamente a Carteis:

\begin{tabular}{|l|l|l|}
\hline \multicolumn{1}{|c|}{$\mathbf{n}^{\circ}$ do Processo } & \multicolumn{1}{c|}{ Julgamento } & \multicolumn{1}{c|}{ Mercado Relevante afetado } \\
\hline $08012.001280 / 2001-35$ & PROCEDENTE & $\begin{array}{l}\text { INTERIOR RIO GRANDE } \\
\text { DO SUL }\end{array}$ \\
\hline $08012.021738 / 96-92$ & PROCEDENTE & GOIAS \\
\hline $08012.006397 / 97-02$ & PROCEDENTE & PIAUI \\
\hline $08000.021976 / 1997-51$ & PROCEDENTE & LONDRINA - PARANÁ \\
\hline $08012.001098 / 2001-84$ & PROCEDENTE & NACIONAL \\
\hline $08012.004036 / 2001-18$ & PROCEDENTE & SANTA CATARINA \\
\hline
\end{tabular}

9 No ano de 2001 foram 31 os casos julgados envolvendo a suspeita da prática de cartel. 


\begin{tabular}{|c|l|l|}
\hline \multicolumn{1}{|c|}{$\mathbf{n}^{\mathbf{o}}$ do Processo } & \multicolumn{1}{c|}{ Julgamento } & \multicolumn{1}{c|}{ Mercado Relevante afetado } \\
\hline $08012.004156 / 2001-21$ & PROCEDENTE & MACAPÁ -AMAPÁ \\
\hline $08012.007515 / 2000-31$ & PROCEDENTE & MINAS GERAIS \\
\hline $08012.003083 / 2001-51$ & PROCEDENTE & CAMPINAS - SP \\
\hline
\end{tabular}

Tabela 4: Processos de Cartel Julgados pelo CADE em 2003. Fonte: www.cade.gov.br

Ao contrário de uma parcela reduzida de condenaçóes como se observava nos anos de 2000, 2001 e 2002, o ano de 2003 foi responsável por um aumento bastante significativo no quantitativo de condenaçóes uma vez que 09 (nove) processos sofreram condenação efetiva pelo CADE. As razóes do aumento também podem se dever aos mesmos fatores elencados no tópico 3.3 .

\subsection{Casos de Cartel Condenados em 2004}

No ano de 2004 foram identificados os seguintes casos envolvendo a prática de cartel:

\begin{tabular}{|c|l|l|}
\hline \multicolumn{1}{|c|}{$\mathbf{n}^{\mathbf{0}}$ do Processo } & \multicolumn{1}{|c|}{ Julgamento } & Mercado Relevante afetado \\
\hline $08012.009987 / 1998-13$ & PROCEDENTE & SERGIPE \\
\hline $08012.004860 / 2000-01$ & PROCEDENTE & DISTRITO FEDERAL \\
\hline
\end{tabular}

Tabela 5: Processos de Cartel Condenados pelo CADE em 2004. Fonte: www.cade.gov.br

Ao contrário de 2003 o ano de 2004 foi caracterizado tanto pela redução de julgados sobre o tema como por uma queda acentuada no número de condenaçóes. Esses dados revelam, talvez, que a complexa análise de condutas cartelizadas varia muito conforme cada caso, não sendo possível identificar um padráo comportamental visto que em referido ano apenas 2 (dois) processos sofreram condenação.

\subsection{Casos de Cartel Condenados em 2005}

Em 2005 constatou-se a presença dos seguintes casos com condenação pela prática de cartel:

\begin{tabular}{|c|l|l|}
\hline \multicolumn{1}{|c|}{$\mathbf{n}^{\mathbf{o}}$ do Processo } & \multicolumn{1}{|c|}{ Julgamento } & \multicolumn{1}{c|}{ Mercado Relevante afetado } \\
\hline $08012.002097 / 1999-81$ & PROCEDENTE & RIO DE JANEIRO \\
\hline $08012.009160 / 2002-67$ & PROCEDENTE & Paranavaí/PR \\
\hline $08012.003068 / 2001-11$ & PROCEDENTE & GOIAS \\
\hline
\end{tabular}




\begin{tabular}{|c|l|l|}
\hline \multicolumn{1}{|c|}{$\mathbf{n}^{\mathbf{o}}$ do Processo } & \multicolumn{1}{|c|}{ Julgamento } & \multicolumn{1}{c|}{ Mercado Relevante afetado } \\
\hline $08012.002153 / 2000-72$ & PROCEDENTE & SÃO PAULO \\
\hline $08012.002127 / 2002-14$ & PROCEDENTE & SÃO PAULO \\
\hline $08012.004086 / 2000-21$ & PROCEDENTE & SÃO PAULO \\
\hline
\end{tabular}

Tabela 6: Processos de Cartel Condenados pelo CADE em 2005. Fonte: www.cade.gov.br

Mais uma vez revelando uma ausência de padrão, observa-se na tabela acima que em 2005 somente 6 (seis) casos sofreram condenação.

\subsection{Casos de Cartel Condenados em 2006}

No ano de 2006 restaram identificados os seguintes julgados referentes a prática de cartel:.

\begin{tabular}{|c|l|l|}
\hline \multicolumn{1}{|c|}{$\mathbf{n}^{\text {o do Processo }}$} & \multicolumn{1}{|c|}{ Julgamento } & \multicolumn{1}{c|}{ Mercado Relevante afetado } \\
\hline $08012.000099 / 2003-73$ & PROCEDENTE & SÃO PAULO \\
\hline $08012.007042 / 2001-33$ & PROCEDENTE & BAHIA \\
\hline $08012.001112 / 2000-42$ & PROCEDENTE & URUGUAIANA / RS \\
\hline $08012.001692 / 2005-07$ & PROCEDENTE & SÃO PAULO \\
\hline $08012.007406 / 2001-85$ & PROCEDENTE & MOGI-GUAÇU /SP \\
\hline
\end{tabular}

Tabela 7: Processos de Cartel Condenados pelo CADE em 2006. Fonte: www.cade.gov.br

Em 2006 foram 05 (cinco) os julgados envolvendo a prática de cartel que sofreram condenação pelo CADE.

\subsection{Casos de Cartel Condenados em 2007}

No ano de 2007 foram identificados os seguintes julgados sobre conduta cartelizada que sofreram condenação:

\begin{tabular}{|c|c|c|}
\hline no do Processo & \multicolumn{1}{|c|}{ Julgamento } & \multicolumn{1}{c|}{ Mercado Relevante afetado } \\
\hline $08012.007602 / 2003-11$ & PROCEDENTE & PORTO ALEGRE / RS \\
\hline
\end{tabular}

Tabela 8: Processos de Cartel Julgados pelo CADE em 2007. Fonte: www.cade.gov.br

No ano de 2007 apenas 1 (hum) processo envolvendo a prática de cartel gerou condenação embora tenham sido julgados 17 (dezessete) casos sobre a matéria pelo Conselho. 


\subsection{Casos de Cartel Condenados em 2008}

No ano de 2008 foram identificados os seguintes casos:

\begin{tabular}{|c|l|l|}
\hline \multicolumn{1}{|c|}{$\mathbf{n}^{\mathbf{o}}$ do Processo } & \multicolumn{1}{|c|}{ Julgamento } & \multicolumn{1}{c|}{ Mercado Relevante afetado } \\
\hline $08012.006019 / 2002-11$ & PROCEDENTE & $\begin{array}{l}\text { TRIANGULO MINEIRO / } \\
\text { MG }\end{array}$ \\
\hline $08012.000283 / 2006-66$ & PROCEDENTE & INTERIOR RS \\
\hline
\end{tabular}

Tabela 9: Processos de Cartel Condenados pelo CADE em 2008. Fonte: www.cade.gov.br

Pode-se deduzir, a partir desses dados, um baixo índice de condenação do CADE por prática de Cartel no ano de 2008, correspondendo a apenas 2 (duas) condenaçóes.

\subsection{Casos de Cartel Condenados em 2009}

No ano de 2009 ficou constatado apenas um caso de condenação pela prática de cartel. Trata-se do Processo Administrativo no 08012.006241/1997-03. Referido processo cuidou de alinhamento de preços praticados por farmácias e drogarias situadas no Distrito Federal correspondendo, dessa forma, a cartel específico com setorização bem delimitada tanto do ponto de vista econômico como geográfico.

\begin{tabular}{|c|c|c|}
\hline no do Processo & Julgamento & Mercado Relevante afetado \\
\hline $08012.006241 / 1997-03$ & PROCEDENTE & Distrito Federal \\
\hline
\end{tabular}

Tabela 10: Processos de Cartel Condenados pelo CADE em 2009. Fonte: www.cade.gov.br

Pode-se deduzir, a partir desses dados, um baixo índice de condenação do CADE por prática de Cartel no ano de 2009. Com base em dados disponíveis no portal eletrônico do CADE dos 18 (dezoito) processos administrativos julgados em 2009 apenas 2 (dois) resultaram em condenaçóes concretas sendo além do já apresentado o processo no $08012.003805 / 2004-10^{10}$ que condenou por prática de abuso do poder econômico. Mesmo nesse cenário é possível observar, também, que os cartéis correspondem a uma das práticas que mais movimenta o SBDC uma vez que dos 18 (dezoito) processos julgados 11 (onze) versavam sobre a possível prática de conduta cartelizada.

10 Processo instaurado em face de representação apresentada pela Primo Schincariol Indústria de Cervejas e Refrigerantes S/A (schincariol) contra práticas da Companhia de Bebidas das américas (AMBEV). Conselheiro Relator: Fernando Magalhães Furlan. 


\subsection{Casos de Cartel Condenados em 2010}

No ano de 2010 comparativamente ao ano de 2009 houve aumento no número de processos administrativos que causaram a condenação dos representados pela prática de cartel conforme se observa abaixo.

\begin{tabular}{|c|c|c|}
\hline no do Processo & Julgamento & Mercado Relevante afetado \\
\hline $08012.009922 / 2006-59$ & PROCEDENTE & Cuiabá e Várzea Grande - MT \\
\hline $08012.004484 / 2005-51$ & PROCEDENTE & Nacional* $^{*}$ \\
\hline $08012.009888 / 2003-70$ & PROCEDENTE & Nacional \\
\hline
\end{tabular}

Tabela 11: Processos de Cartel Julgados pelo CADE em 2010. Fonte: www.cade.gov.br

Em relação ao processo administrativo no . 08012.004484/2005-51 destaca-se que, em verdade, houve condenação da empresa representada em razão da realização de convite à cartelização da empresa representante não tendo ocorrido, nesse caso em específico, as consequências nefastas decorrentes da cartelização de um mercado.

No que tange aos demais processos, observa-se que o de no 08012.009922/2006-59 corresponde a um cartel de âmbito local, atingindo o mercado de auto-escolas de dois municípios do estado de Mato Grosso. Em relação ao processo no 08012.009888/200370 tem-se um cartel de âmbito nacional havendo um fato interessante em relação a esta conduta que corresponderá a um dos únicos casos encontrados nesta pesquisa de ação judicial voltada a obter reparaçáo dos danos causados em decorrência da prática junto ao Tribunal de Justiça de Minas Gerais (Tabela 10, adiante - Tópico 04).

Mais uma vez reforça-se o alto índice de análise da conduta de cartel por parte do SBDC uma vez que, em 2010, dos 20 (vinte) processos julgados pelo CADE 11 (onze) correspondiam a possíveis práticas de cartel.

\subsection{Casos de Cartel Julgados em 2011}

No ano de 2011 não foi localizado nenhum processo administrativo que acarretasse condenação pela prática de cartel, conforme se observa na tabela abaixo pelo símbolo (-X-).

\begin{tabular}{|c|c|c|}
\hline $\mathbf{n}^{\mathbf{o}}$ do Processo & Julgamento & Mercado Relevante afetado \\
\hline$-\mathrm{X}-$ & $-\mathrm{X}-$ & $-\mathrm{X}-$ \\
\hline
\end{tabular}

Tabela 12: Processos de Cartel Julgados pelo CADE em 2011. Fonte: www.cade.gov.br

Tal quadro pode decorrer, em verdade, do período de reestruturação pelo qual passou o SBDC nos anos de 2011 e 2012 em decorrência da mudança de estrutura 
promovida pela Lei 12.529/2011 que revogou a Lei 8.884/94, conforme demonstrado no tópico 02 deste trabalho. Outro ponto que merece destaque é que como as mudanças da Lei atingiam mais diretamente as análises de Atos de Concentração - ACs, o SBDC foi muito demandado nesse período ${ }^{11}$ de transição por empresas que buscaram efetivar seus atos de concentração ainda sob a vigência da Lei antiga, fato que prejudicou a análise de Processos Administrativos de Condutas anticoncorrenciais.

Apenas a título de ilustração, observou-se que, dos 15 (quinze) processos administrativos julgados em 2011, nenhum acarretou em condenação, tendo sido, em sua maioria, processo arquivado ou prescrito. Mais uma vez, a conduta predominante é o de cartel, uma vez que desses 15 (quinze) processos 9 (nove) correspondiam a possíveis práticas da referida conduta.

\subsection{Casos de Cartel Julgados em 2012}

No ano de 2012, ainda impactado pelas mudanças estruturais da nova Lei, o SBDC julgou com decisão condenatória apenas um processo administrativo relativo à prática de cartel conforme demonstrado na tabela abaixo.

\begin{tabular}{|c|c|c|}
\hline no do Processo & Julgamento & Mercado Relevante afetado \\
\hline $08012.004702 / 2004-77$ & Procedente & Nacional \\
\hline
\end{tabular}

Tabela 13: Processos de Cartel Julgados pelo CADE em 2012. Fonte: www.cade.gov.br

Mais uma vez corresponde a um cartel de âmbito nacional relativo ao mercado de comercialização de água oxigenada. Aspecto relevante desse processo é que o mesmo se iniciou a partir do uso do mecanismo de Acordo de Leniência ${ }^{12}$. Em 2012 dos 15 (quinze) processos administrativos julgados pelo CADE 6 (seis) tratavam de investigação pela prática de possível cartel.

\subsection{Casos de Cartel Julgados em 2013}

No ano de 2013 houve incremento no julgamento de processos administrativos de condutas pelo CADE. Já contando o SBDC como a nova estrutura consolidada, e com atuação eficiente da Superintendência-Geral, foram apreciados pelo CADE 37 (trinta e

11 Somente para que se possa ter uma ideia, segundo balanço do CADE, (2012), disponível em www.cade. gov.br), em 2011 houve 716 processos administrativos de Atos de Concentração julgados pelo CADE. Em 2012, o número foi de 825 sendo que desses, 723 foram julgados pela Lei 8.884/94 e 102 com base na Lei nova. Já no ano de 2013, o número de ACs julgados foi de apenas 103 Processos, tendo grande parte se resolvido pelo rito sumário, diretamente na Superintendência Geral.

$12 \mathrm{O}$ acordo de Leniência está previsto no art. 86 da Lei 12.529/11 e permite que o CADE firme acordo com empresas ou pessoas participantes de cartéis que estejam dispostas a cooperar totalmente com as investigação em troca de isenções de punição. 
sete) processos administrativos dos quais 15 (quinze) correspondiam a possível prática de cartel. Dentro desse universo houve a condenação por parte do CADE em 7 (sete) processos administrativos conforme disposto em tabela abaixo.

\begin{tabular}{|c|c|c|}
\hline no do Processo & Julgamento & Mercado Relevante afetado \\
\hline $08012.003745 / 2010-83$ & PROCEDENTE & Nacional \\
\hline $08012.004039 / 2001-68$ & PROCEDENTE & Sobradinho-DF \\
\hline $08012.010215 / 2007-96$ & PROCEDENTE & Caxias do Sul - RS \\
\hline $08012.00749 / 2009-39$ & PROCEDENTE & Santa Maria - RS \\
\hline $08012.004573 / 2004-17$ & PROCEDENTE & Santa Maria - RS \\
\hline $08012.011668 / 2007-30$ & PROCEDENTE & $\begin{array}{c}\text { Londrina - PR e Região } \\
\text { Metropolitana }\end{array}$ \\
\hline $08012.003874 / 2009-38$ & PROCEDENTE & Minas Gerais - MG \\
\hline
\end{tabular}

Tabela 14: Processos de Cartel Julgados pelo CADE em 2013. Fonte: www.cade.gov.br

Dos processos acima apontados tem-se que apenas um deles corresponde a um cartel de âmbito nacional (Processo $\mathrm{n}^{\mathrm{o}} .:$ 08012.003745/2010-83) sendo que os seis demais tratam-se de cartéis que afetam locais específicos como: Município de Sobradinho - DF; Cidades de Caxias do Sul e Santa Maria - RS; regiáo metropolitana e Município de Londrina - PR; e Estado de Minas Gerais.

Diante desse cenário percebe-se que, na maioria dos casos, os cartéis são localizados, até havendo a ocorrência de cartéis de âmbito nacional que se tornam mais difíceis de ocorrer e de coibir, por conta da necessidade de combinação e monitoramento das práticas.

Demonstrado, assim, as condenaçóes aplicadas pelo CADE em casos de Cartel no período 2000-2013. No tópico a seguir, procura-se analisar o perfil dessas condenaçóes no que diz respeito ao mercado geográfico relevante afetado, ou seja, o local onde a conduta foi praticada.

\section{Análise dos Casos por Delimitação Geográfica}

O Brasil como é cabido consistem em um país de dimensōes continentais. Conta com um território aproximado de $\mathbf{8 . 5 1 5 . 7 6 7 , 0 4 9} \mathbf{~ k m}^{2}$, dividido em 4 regióes: Norte, Nordeste, Centro-oeste, Sul e Sudeste, contando com 27 estados e 1 distrito federal. Consiste em uma federação formada pela união indissolúvel de união, estados e municípios ${ }^{13}$. (IBGE, 2013)

13 Art. 10 CRFB/88: Art. 10 A República Federativa do Brasil, formada pela união indissolúvel dos Estados e Municípios e do Distrito Federal, constitui-se em Estado Democrático de Direito e tem como 
Além da vastidão territorial o Brasil é um país de profundas desigualdades no campo econômico. Segundo o IBGE o Produto Interno Bruto no Brasil foi de R\$ 5,52 Trilhóes de Reais, sendo que desta quantia $55,1 \%$ correspondem apenas a região sudeste, sendo $16,2 \%$ da região Sul e o restante dividido em 5,3\% da regiáo Norte, 13,6\% regiáo Nordeste e 9,8\% região Centro Oeste. Somente esse dado já é suficiente para indicar o quão desigual é a situação entre as regiōes e os estados do Brasil

A partir dessa perspectiva, nos tópicos a seguir, conforme os dados apontados no item 3 deste trabalho será analisada a distribuição regional de casos em que a prática de cartel sofreu condenação. A análise será dividida em quantitativo nacional e regional.

De início cumpre destacar que foram identificados em 2000 e 2013 um total de 53 (cinquenta e três) casos de condenação pela prática de cartel sendo esse o índice quantitativo de referência a ser utilizado em cada tópico a seguir. Dos 53 apenas 2 (dois) processos não tiveram sua delimitação geográfica identificada por esta pesquisa em razão da ausência de documentação disponível no portal eletrônico do CADE, o que corresponde a um percentual de $3,77 \%$ dos processos analisados.

\subsection{Casos de Delimitação Nacional}

Foram identificados 7 (sete) casos de delimitação nacional. Dadas as perspectivas da prática de cartel, considerando se tratar o Brasil um país de dimensóes continentais, o nível de sofisticação de um cartel necessita atingir para funcionar em todo território nacional é significativo vez que o cartel demanda constante comunicação e verificação.

Diante dessa perspectiva entende-se como razoável a quantidade de casos que correspondem a um percentual de $13,21 \%$ do total de casos analisados. Os processos analisados foram: 08012.000487/2000-40; 08012.006504/97-11; 08012.001098/200184; $\quad 08012.004484 / 2005-51 ; \quad 08012.009888 / 2003-70 ; \quad 08012.004702 / 2004-77$; $08012.003745 / 2010-83$.

\subsection{Casos de Delimitação nas Regiões Norte e Nordeste}

As regióes Norte e Nordeste do Brasil são as que menos sofreram condenaçóes com base em processo administrativos que analisaram casos de cartel no Brasil no período em que a pesquisa foi realizada. A região Norte contou com apenas 1 Caso - Processo 08012.004156/2001-21, na cidade de Macapá, estado do Amapá. Já a região Nordeste contou com 6 (seis) processos condenados.

fundamentos: I - a soberania; II - a cidadania; III - a dignidade da pessoa humana; IV - os valores sociais do trabalho e da livre iniciativa; V - o pluralismo político. Parágrafo único. Todo o poder emana do povo, que o exerce por meio de representantes eleitos ou diretamente, nos termos desta Constituiçáo. 
Tais números revelam um insignificante patamar de 1,89\% de condenação para regiāo Norte e de $11,32 \%$ de condenação para região Nordeste. Perceba-se que as duas regióes somadas não alcança o mesmo percentual de processos nacionais, chegando apenas a 13,20\%. Os processos do Nordeste com os respectivos estados foram: 08012.006492/9725 Rio Grande do norte; 08012.004372/2000-70 Ceará; 08012.004373/2000-32 Ceará; 08012.006397/97-02 Piauí; 08012.009987/1998-13 Sergipe.

\subsection{Casos de Delimitação nas Regiões Centro-Oeste e Sul}

As regiōes Sul e Centro Oeste são das mais afetadas pela atuação da autoridade antitruste no período analisado. A primeira sendo responsável por 14 casos, que correspondem a expressivos $26,42 \%$ dos casos condenados; já a segunda obteve 8 condenaçóes que correspondem a $15,09 \%$ dos casos.

Os processos da região Sul foram: 08012.003128/98-67, em Florianópolis; 08012.007044/99-00 estado do Paraná; 08012.002299/2000-18 estado de Santa Catarina; 08012.001280/2001-35 interior do Rio Grande do Sul; 08000.021976/1997-51 Londrina no Paraná; 08012.004036/2001-18; Santa Catarina; 08012.009160/2002-67 Paranavaí; 08012.001112/2000-42 Uruguaiana-RS; 08012.007602/2003-11 Porto Alegre - RS; 08012.000283/2006-66 Interior do Rio Grande do Sul; 08012.010215/200796 Caxias do Sul; 08012.00749/2009-39 Santa Maria - RS; 08012.004573/2004-17 Santa Maria - RS; 08012.011668/2007-30 Londrina e Região Metropolitana.

Já os processos da região Centro Oeste correspondem a: 08000.015515/9702 Mato Grosso do Sul; 08012.004712/2000-89 Goiás; 08012.021738/96-92 Goiás; 08012.004860/2000-01 Distrito Federal; 08012.003068/2001-11 Goiás; 08012.006241/1997-03 Distrito Federal; 08012.009922/2006-59 Cuiabá e Várzea Grande; 08012.004039/2001-68 Distrito Federal.

A região sul é tradicionalmente conhecida pela busca na efetivação do direito podendo ter como uma justificativa da quantidade de casos o fato de a população ter o costume de denunciar eventuais práticas ilegais e abusivas. Já a região Centro Oeste conta, entre outras vantagens, com a proximidade física dos órgáos de defesa da concorrência que funcionam apenas na cidade de Brasília - Distrito Federal.

\subsection{Casos de Delimitação na Região Sudeste}

Por fim traz-se a região sudeste, maior afetada pela atuação da autoridade antitruste em matéria de cartel. Dos processos condenados 15 (quinze) correspondiam a práticas realizadas nessa regiáo o que acarreta um percentual de $28,30 \%$ dos casos. 
Os processos da regiáo sudeste foram: 08012.000792/99-16 São Paulo; 08012.006030/99-51 Campinas - SP; 08000.022994/97-79 São Paulo; 08000.026056/96-30 Rio de Janeiro - RJ; 08012.007515/2000-31 - Minas Gerais; 08012.003083/2001-51 Campinas - SP; 08012.002153/2000-72 São Paulo - SP; 08012.002127/2002-14 São Paulo - SP; 08012.004086/2000-21 São Paulo - SP; 08012.002097/1999-81 Rio de Janeiro - RJ; 08012.007406/2001-85 Mogi das Cruzes - SP; 08012.001692/2005-07; São Paulo - SP; 08012.000099/2003-73 São Paulo - SP; 08012.006019/2002-11 Triangulo Mineiro; 08012.003874/2009-38 Minas Gerais.

Abaixo apresenta-se um gráfico demonstrativo do quantitativo de processos analisados e sua delimitação geográfica:

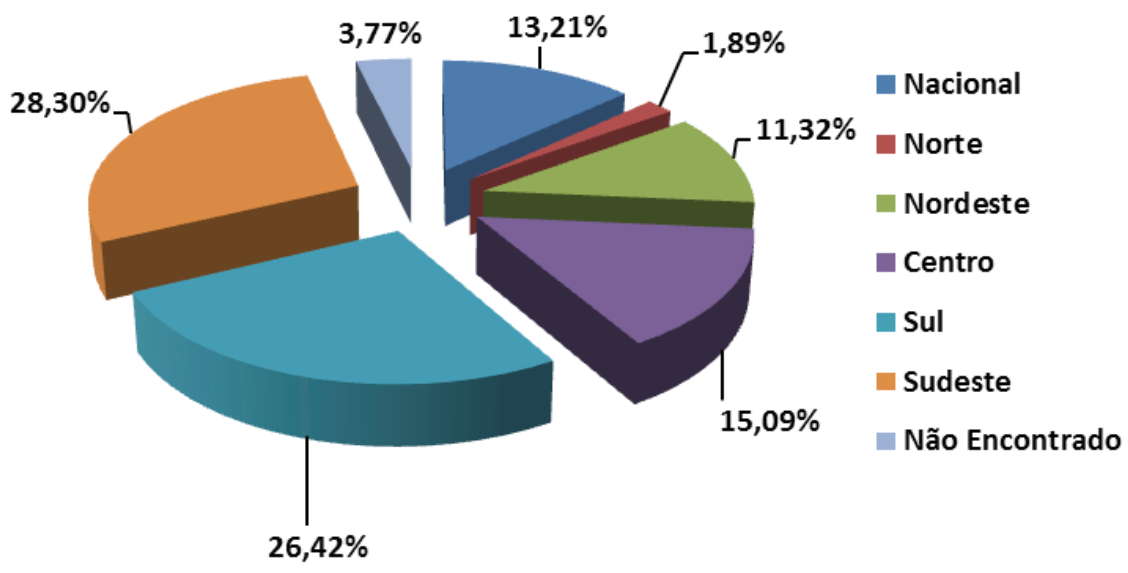

\section{Conclusões}

A economia de mercado instituída sob a égide da Constituição da República Federativa do Brasil de 05 de outubro de 1988 - CRFB/88 exige a intervenção estatal para tentativa de promoção do equilíbrio entre a livre iniciativa e a preservação da liberdade dos agentes econômicos e os interesses sociais a serem efetivados pelo Estado como valorização do trabalho humano e a dignidade do individuo.

Para um funcionamento eficiente e equilibrado dos mercados é essencial a proteção da livre concorrência de forma que permita, efetivamente, a existência de um equilíbrio entre os agentes econômicos nas relaçóes de trocas promovidas, sob pena de se promover uma iniquidade e uma situaçáo economicamente ineficiente com baixa alocaçáo de recursos escassos e prejuízos à sociedade, em geral, em detrimento de poucos interesses privados. 
O Sistema Brasileiro de Defesa da Concorrência - SBDC, por intermédio de sua estrutura administrativa desempenha papel fundamental na efetivação e na defesa de um ambiente concorrencial equilibrado, contribuindo sobremaneira para possibilitar o desenvolvimento econômico, atrelado a ganhos de perspectivas sociais que resultem em melhorias para todos os cidadãos brasileiros. A Lei 12.529/2011 vem, assim, somar nesse cenário revitalizando a estrutura interna do Conselho Administrativo de Defesa Econômica e promovendo uma maior eficiência na atuação do órgão tanto no controle de estruturas como no controle de condutas de infração à ordem econômica.

Especificamente em relação aos cartéis observa-se que, dentre os casos julgados pelo Tribunal Administrativo nos últimos anos (2009-2013), a conduta aparece como a mais recorrentemente submetida à apreciação do conselho, representando um total de 52 processos dos 105 processos administrativos analisados o que corresponde a 49,52\% do total de processos de infrações à ordem econômica julgados pelo CADE neste período.

Outro aspecto relevante em relação aos cartéis é que, em sua maioria, se revelam como condutas de âmbito local, o que ocorreu em 87,09\% dos casos de cartel condenados pelo $\mathrm{CADE}^{14}$ dentro do período analisado neste artigo.

Tal perspectiva deve decorrer da maior facilidade de interação entre os participantes do conluio em mercados menores sendo certo que também há ocorrência de condenação por cartéis de âmbito nacional. Essa incidência local dos cartéis reforça a hipótese apresentada por esta pesquisa de que a participação da sociedade civil, consciente da existência de regras de defesa do ambiente concorrencial será fundamental para aplicação concreta dos comandos normativos existentes e efetivação do princípio constitucional da livre concorrência.

É importante observar a ausência de uma uniformidade tanto na quantidade de processos julgados e que sofreram condenaçóes por cartel a cada ano, além da ausência de uma equânime distribuição nacional na análise dos casos. Somente a região Sul e Sudeste abarcam 54,72\% dos casos analisados que o renega às regiôes Norte e Nordeste uma atuação reduzida ou quase inexpressiva da autoridade antitruste brasileira.

Pode haver a alegação de que como as regióes Sul e Sudeste produzem mais é natural que tenham mais empresas e maior incidência de prática de infração da ordem econômica mas é importante lembrar que o desenvolvimento econômico pressupóe uma economia de mercado efetivamente competitiva onde se possa efetivamente exercer a livre iniciativa sem a limitação importa por conchavos ou conluios.

Outra possível discussão seria a adoção de uma estrutura descentralizada do SBDC, possivelmente, através de superintendências regionais, objetivando promover uma maior

14 Vide Gráfico item 4.4. 
proximidade do Sistema com as diversas regiôes do país, sobretudo, as Regióes Nordeste e Norte que, como visto, são as que menos contam com atuação antitruste havendo ainda a necessidade de se disseminar a cultura da defesa da concorrência pelo país para que se possibilite uma maior participação da população no controle e denuncia dos casos.

A presente pesquisa não objetiva ser definitiva consistindo, desse modo, em um estudo exploratório para que se observe com maior cuidado e atenção a necessidade de difusão da política da concorrência junto à sociedade civil, congregando para tal a participação do Poder Público, do SBDC, do Ministério Público, da Ordem dos Advogados e demais agentes que possam contribuir para o alcance de um mercado verdadeiramente competitivo e livre de ações ilícitas e perniciosas para a sociedade brasileira.

\section{Referências}

BRASIL. Constituição (1988). Constituição da República Federativa do Brasil. Disponível em: <https://www.planalto.gov.br/ccivil_03/Constituicao/Constitui\%C3\%A7ao.htm>. Acesso em: 02 mar. 2014.

BRASIL. Lei no.: 12.529 de 30 de novembro de 2011. Estrutura o Sistema Brasileiro de Defesa da Concorrência; dispóe sobre a prevenção e repressão às infraçóes contra a ordem econômica; altera a Lei no 8.137 , de 27 de dezembro de 1990, o Decreto-Lei no 3.689, de 3 de outubro de 1941 - Código de Processo Penal, e a Lei no 7.347, de 24 de julho de 1985; revoga dispositivos da Lei no 8.884, de 11 de junho de 1994, e a Lei no 9.781, de 19 de janeiro de 1999; e dá outras providências. Disponível em: <http://www.planalto.gov.br/ccivil_03/_ato2011-2014/2011/Lei/L12529.htm>. Acesso em: 02 mar. 2014.

BRASIL. Lei no ${ }^{\circ}$ 8.884, de 11 de junho de 1994. Transforma o Conselho Administrativo de Defesa Econômica (Cade) em Autarquia, dispóe sobre a prevenção e a repressão às infraçôes contra a ordem econômica e dá outras providências (Revogado). Disponível em: <http://www.planalto.gov.br/ccivil_03/Leis/L8884.htm>. Acesso em: 02 mar. 2014.

BRASIL. Lei $n^{\circ}$. 8.078, de 11 de setembro de 1990. Dispóe sobre a proteção do consumidor, e dá outras providências. Disponível em: <https://www.planalto.gov.br/ ccivil_03/Leis/L8078.htm>. Acesso em: 02 mar. 2014.

BRASIL. Lei $\mathrm{n}^{\circ}$. 8.137, de 27 de dezembro de 1990. Define crimes contra a ordem tributária, econômica e contra as relaçôes de consumo, e dá outras providências. Disponível em: < http://www.planalto.gov.br/ccivil_03/leis/l8137.htm>. Acesso em: 02 mar. 2014.

BRASIL. Instituto Brasileiro de Geografia e Estatística - IBGE. Indicadores e geociências. Disponível em: <http://www.ibge.gov.br/home/>. Acesso em: 02 mar. 2014. 
EHRHARDT JUNIOR, Marcos Augusto Albuquerque. As funçóes da boa-fé e a construção de deveres de conduta nas relaçóes privadas. Revista Pensar, v. 18, n. 2, p. 551-586, maio/ago. 2013.

FORGIONI, Paula A. Os fundamentos do antitruste. São Paulo, Revista dos Tribunais, 2012.

GICO JR., Ivo Teixeira. Cartel: teoria unificada da colusão. São Paulo: Lex, 2007.

GOLDBERG, Daniel Krepel. Poder de compra e política antitruste. São Paulo: Singular, 2006.

GRAU, Eros Roberto. A ordem econômica na constituição de 1988. São Paulo: Malheiros, 2004.

HOVENKAMP, Herbert. Federal Antitrust Policy: the law of competition and its practice. St. Paul: THOMSON, 2005.

MINISTÉRIO DA JUSTIÇA. Secretaria de Direito Econômico. Combate a cartéis e Programa de Leniência. 2009. Disponível em: <http://www.cade.gov.br/upload/ Cartilha\%20Leniencia\%20SDE_CADE.pdf>. Acesso em: Acesso em: 20 fev. 2014.

MOTA, Massimo. Competition Policy: theory and practice. New York: Cambridge University, 2004.

SADDI, Jairo; PINHEIRO, Armando Castelar. Direito, economia e mercados. Rio de Janeiro: Elsevier, 2005.

SALOMÃO FILHO, Calixto. Regulação e concorrência: estudos e pareceres. São Paulo: Malheiros, 2002. 